\title{
Flight Plasma Diagnostics for High-Power, Solar-Electric Deep-Space Spacecraft
}

\author{
Lee Johnson, Maria De Soria-Santacruz \\ Pich, David Conroy, and Robert Lobbia \\ Jet Propulsion Laboratory \\ California Institute of Technology \\ 4800 Oak Grove Dr., Pasadena, CA 91109 \\ 818-354- $\{9878,8736,5002,0278\}$ \\ \{lee.k.johnson, mpich, david.g.conroy, \\ robert.b.lobbia\}@jpl.nasa.gov
}

\author{
Wensheng Huang and Maria Choi \\ NASA Glenn Research Center \\ 21000 Brookpark Rd., Cleveland, \\ OH 44135 \\ 216-433- $\{5557,8690\}$ \\ \{wensheng.huang, maria.choi\} \\ @nasa.gov
}

\author{
Michael J. Sekerak \\ NASA Goddard Space Flight \\ Center \\ 8800 Greenbelt Rd \\ Greenbelt, MD 20771 \\ 301-286-8729 \\ michael.sekerak@nasa.gov
}

\begin{abstract}
NASA's Asteroid Redirect Robotic Mission (ARRM) mission concept plans included a set of plasma and space environment instruments, the Plasma Diagnostic Package (PDP), to fulfill ARRM requirements for technology extensibility to future missions. The PDP objectives were divided into the classes of 1) Plasma thruster dynamics, 2) Solar array-specific environmental effects, 3) Plasma environmental spacecraft effects, and 4) Energetic particle spacecraft environment. A reference design approach and interface requirements for ARRM's PDP was generated by the PDP team at JPL and GRC. The reference design consisted of redundant single-string avionics located on the ARRM spacecraft bus as well as solar array, driving and processing signals from multiple copies of several types of plasma, effects, and environments sensors distributed over the spacecraft and array. The reference design sensor types were derived in part from sensors previously developed for USAF Research Laboratory (AFRL) plasma effects campaigns such as those aboard TacSat-2 in 2007 and AEHF-2 in 2012.
\end{abstract}

ARRM project leadership also encouraged the PDP team to convene a team of topical subject matter experts from across the country to review and confirm the reference design and to consider effective alternatives and/or enhancements to the reference design. This activity was proposed and accepted as an interactive, informal JPL "A-team" study and a cadre of 25 participants gathered in early 2017 for discussions. The outcome of the two-day A-team study was that the PDP reference design would allow the most important induced-environment unknowns to be measured in the appropriate space environment. Another outcome addressed technology developments of new or improved space plasma environmental sensors. The A-team study concluded that selected developments would lead to improved measurements that could efficiently provide important and otherwise unavailable information about plasma thruster operation in the space environment as well as the plasma induced spacecraft environment. Specifically, the A-team group recommended greater sensor diversity, by inclusion of deployed sensor capabilities in the thruster plume, or by occasional gimbaling of the thruster(s) toward the sensor arrays. The A-team also recommended developing high-speed probes, optical plasma probes, energy selective probes, and direct erosion/deposition sensors, among others; and recommended the inclusion of cameras as well as, since ARRM was to be recovered in cis-lunar orbit by a crewed mission, astronaut assessments of thruster induced environments and collection of sample coupons.

Overall, the PDP A-team study provided a clear, consensussupported validation of the reference design PDP approach and pointed out important directions for future flight plasma sensor development.

\section{TABLe of Contents}

TABLE OF CONTENTS 1

1. INTRODUCTION .................................................................... 1

2. PDP REFERENCE CONFIGURATION ................................. 2

3. IMPLEMENTATION STRATEGY ...........................................5

4. A-TEAM STUDY METHOdOLOGY .....................................6 6

5. A-TEAM RESULTS AND FINDINGS .................................... 7

6. DISCUSSION AND ANALYSIS .............................................. 11

7. RECOMMENDATIONS AND CONCLUSION......................... 14

ACKNOWLEDGMENTS.......................................................... 14

REFERENCES................................................................... 14

BIOGRAPHY …....................................................................... 15

\section{INTRODUCTION}

Plasma plumes from high-power electric thrusters are known to interact with solar arrays and other materials commonly found on spacecraft surfaces [1]-[6]. Satisfactory characterizations of these potentially adverse effects are beyond the capabilities of ground-based test facilities because (1) the background pressure in vacuum chambers is typically orders of magnitude higher than in flight ([2], [6]) and (2) energetic thruster ions sputter the chamber walls, generating a deposition environment [7] not present in space. One way to provide good characterizations is to perform applicable plasma diagnostics measurements in space as part of a technology demonstration. This was intended for the Asteroid Redirect Robotic Mission (ARRM) mission concept, which was planned to develop and demonstrate a 40 $\mathrm{kW}$ electric propulsion system as part of a proposal to return asteroid material to lunar orbit for further investigation [8]. ARRM also included technology requirements to demonstrate technology extensibility to propulsion power levels of at least $150 \mathrm{~kW}$. A flight plasma measurements subsystem was seen by the project to be one of the key methods to meet the extensibility requirement in the area of induced spacecraft environments.

This paper begins by presenting the reference design of the PDP for this mission, followed by an explication of the 
acquisition strategy for the subsystem and its relation to previous flight thruster plasma instrumentation. The paper goes on to discuss how the PDP also was the subject of a twoday, independent, community-wide "A-team" study at JPL, where the reference design was reviewed and the relative merits of potential extensions to the reference design discussed. The study outcomes are presented, discussed, and analyzed in the following section. The paper concludes with recommendations for development of specific measurements and sensors to efficiently meet plasma environment technology requirements for generic high-power, solarelectric propulsion (SEP), deep-space vehicles.

The PDP plays a pivotal role in achieving the extensibility of SEP technology as flight results provide the truth data necessary to validate the modeling and ground-test based thruster development and qualification. This familiar 'data triad' (Figure 1) [6], of flight, ground, and physics-based model data establishes the foundation of predictive SEP environmental design to be extended to higher power. Note that while the modeling aspects of the triad are only lightly treated in this description of the PDP and spacecraft environment, the importance of such modeling efforts cannot be overstressed. In other projects, the modeling and diagnostics tasks were combined under the guidance of an 'induced environments science' investigation; however, the modeling effort for ARRM was binned separately from the PDP tasks. Future implementations could consider whether overall project goals are better served by a loose or close coupling between elements of the data triad.

\section{PDP REFERENCE CONFIGURATION}

\section{Background and Rationale}

The ARRM spacecraft bus acquisition approach included provisions for supplying detail to prospective vendors regarding elements of the integrated spacecraft not to be provided by the contracted bus vendor [8]. As a result, the project tasked the PDP team with generating a document describing the PDP elements, spacecraft requirements, and interfaces. Thruster plasma diagnostics were successfully flown on the NASA Deep Space-1 mission [9], which inspired and informed the PDP team. The PDP team was also familiar with several plasma diagnostic subsystems flown by the USAF Research Laboratory (AFRL) to assess thruster interactions on the Tacsat-2 [4] and AEHF-2 [6] spacecraft (members of the PDP team participated directly in those flight projects). At project request, and with PDP team concurrence, AFRL was contacted and asked whether they would share aspects of their applicable systems. AFRL graciously provided information to ARRM about their plasma diagnostic systems. It is worth noting that while the AFRL flight measurements were regarded as ITAR-sensitive (and thus published in closed JANNAF journals), the approach and broad technical aspects of the AFRL plasma diagnostic system, including the sensors, was not considered ITAR sensitive. As a result, ARRM project management concluded that a low-impact implementation of the PDP would substantially use the AFRL sensor approaches. The
PDP team considered avionics options and recommended acquisition of substantially new electronics as described below. Project management had the PDP team source a reference design in support of the spacecraft bus contract activity; the reference design was to include a placeholder for the new electronics and would only utilize sensor approaches that had previously been used by AFRL. Evolutionary development of sensors towards better capabilities or more refined measurements were not included for the reference design.

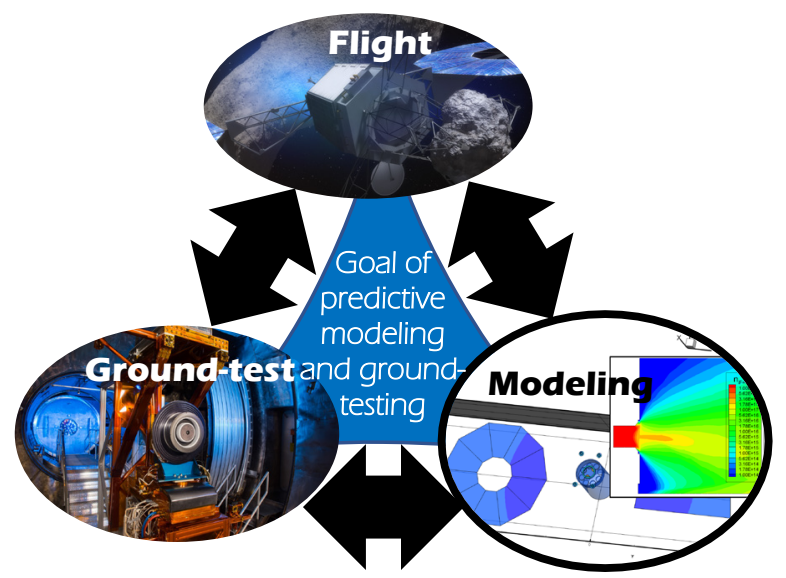

Figure 1. Data Triad of Flight-, Ground-, and Simulated-data

\section{Electronics and Sensors}

The reference PDP was to be an independent spacecraft system aboard the ARRM spacecraft. Sensors were to be distributed widely over the ARRM spacecraft; each sensor would mechanically mount to the spacecraft structure or to a PDP sub-structure holding multiple sensors which in turn was mechanically interfaced to the spacecraft. Electrical connections for sensor excitation or for measured signals were to be made between the sensors and a dedicated PDP avionics unit, the PDP-E. More than one PDP-E was to be flown to provide a measure of system redundancy. Each PDP-E was to be mechanically installed internal to the spacecraft; each was to have independent power, commanding, and data handling. A block diagram of the reference PDP is provided in Figure 2. One relatively unusual measure was also taken to provide the capability for the PDP propulsion system to collect thruster discharge current at high speed. A high-speed current sensor, inductively coupled to the cathode discharge current line, was to be included with the contractor-provided thruster power processor. Specifications were agreed upon by the vendor, the PDP team, and GRC/JPL thruster experts to provide signals with approximately a $100 \mathrm{~Hz}$ to $1 \mathrm{MHz}$ bandwidth, allowing observations of Hall thruster breathing modes with good sampling. This sensor (the PPU Fast Current Sensor) was to be electrically interfaced via a spacecraft-provided cable to the PDP-E, which was planned to have a high-speed data acquisition and storage capability for both the discharge current signal and for the plume ion fast probe. Correlation 
of these two signals would provide insight into fast ion production mechanisms and stability in the Hall thruster.

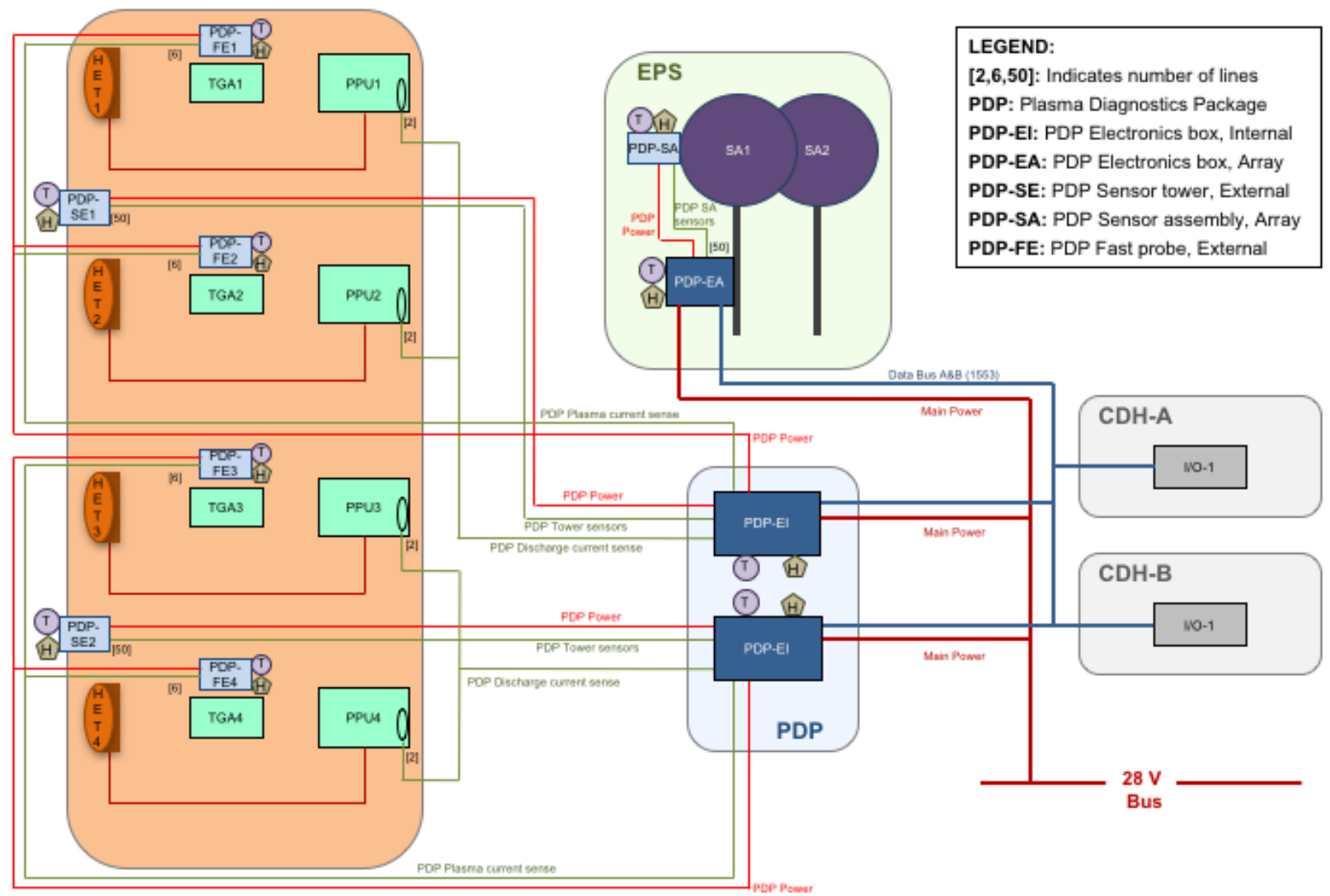

Figure 2. PDP Block Diagram

This unusual configuration, consisting of an interface between a spacecraft payload (the PDP) and critical spacecraft equipment (the thruster PPU) was warranted by the high degree of interest in the measurement from all concerned.

The various PDP sensors require a wide range of electrical excitations and measurements. Some of these are relatively straight-forward scans over a few volts or tens of volts, or relatively robust ( $\mathrm{mA}$ or above) currents, or measurements of typical temperature ranges as usually encountered with space systems; these were not expected to be a challenge for the avionics provider. However, three exceptions to this are (1) high-voltage $(\sim 1 \mathrm{kV})$, low-current $(\mathrm{mA})$ drive voltages required for ion energy sensors, (2) low-current (nA), highvoltage, current-sense capabilities for direct measurement of plume ion content, and (3) signal acquisition electronics of approximately $1 \mathrm{MHz}$ bandwidth to capture transient and periodic fluctuations associated with Hall thruster discharge oscillations. These special capabilities encouraged the PDP team to undertake studies to explore vendor capabilities to provide the PDP-E, described in the implementation strategy section below.
The PDP sensor set was to consist of multiple copies of each sensor type to provide sampling over the various spacecraft and array surfaces and/or thruster plumes. The approach would have grouped sensors together where appropriate (e.g., an erosion measurement would naturally be paired with an ion energy measurement in a location where models indicated a stronger plume ion environment). The reference sensors consisted of these types:

- Planar Langmuir Probe

- Ion Fast Probe

- Ion Flux Sensor

- Ion Retarding Potential Analyzer

- Ion Erosion Sensor

- Surface Deposition Photometric Sensor

- Surface Thermal Radiometer

- $\quad$ Surface Environment Solar Cell

Each sensor type has previously been built and tested either in laboratory or previous flight tests, or both. Each reference sensor type is described below.

The Planar Langmuir Probe is a biased current collector for plasma ions and electrons. Charged particle current is 
measured versus an applied bias potential as it impinges on exposed metal electrodes. In order to reduce geometrical effects from the shape of the plasma boundary created by the bias potential, the inner anode is surrounded by an annular ring guard electrode which is held at the same potential. The PDP-E provides two identical potentials for the anode and the guard, and measures the charged particle current to the anode. The anode current is measured as the potential is scanned at an adjustable rate in either direction over a range, and must operate in all 4 quadrants of current vs. voltage. This transducer has flight heritage with AEHF-2 [6].

The Ion Fast Probe measures wide bandwidth (DC to $1 \mathrm{MHz}$ ) signals from a guarded sensor similar to the Planar Langmuir Probe, employing a different range of bias potentials. Current extracted from the plasma is digitized at rates from $\mathrm{Hz}$ to $\mathrm{MHz}$; the bias potential of the anode can be adjusted to observe either ions or electrons, or to obtain the typical probe IV response curve. The anode current is measured at a fixed bias (e.g. negatively biased with respect to the plasma potential to measure ion density fluctuations) or the potential is scanned at an adjustable rate in either direction over a range, and also is required to operate in all 4 quadrants of current vs. voltage. A similar Ion Fast Probe flew on FalconSat-5 [10] and is slated to launch in 2018 on FalconSat-6.

The Ion Flux Sensor also utilizes a biased current sense anode, but the anode is positioned behind a single screening grid biased to reject plasma electrons as shown in Figure 3. The PDP-E provides independent bias potentials and measures the charged particle current to both the screen and the anode. This sensor has been proven in previous testing to provide some ion density and energy information in regions where the dominant direction of ion influx is not well known.

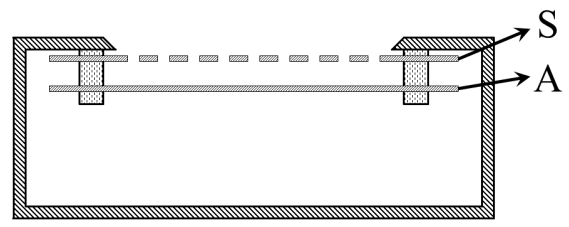

S: Screen grid (rejects electrons)

A: Anode (collects ion current)

Figure 3. Ion Flux Sensor

The Retarding Potential Analyzer (RPA) is a sensor that collects charged particle current to an anode positioned behind a set of electrode grids, as shown in Figure 4. The external electrode is a shield which is allowed to float (no electrical connection). The screen is biased to a negative potential that excludes plasma electrons. Incoming ions then encounter a positive retarding grid which is biased to allow passage only of ions with sufficient kinetic energy to overcome the grid potential. Ions then pass through an electron suppression grid and strike the anode. The suppression grid is biased negative to contain secondary electrons generated at the anode by energetic ions, and the anode is kept near ground potential. The retarding potential is scanned at an adjustable rate in either direction over a range as the current is collected on the anode to measure ion current as a function of minimum kinetic energy. The PDP-E provides the sensor bias potentials to the screen, retarding, and suppression grids, and measures the ion current to the screen and anode. Both the Ion Flux Sensor and the RPAs derive heritage from DS-1 [9], TacSat-2 [4], and AEHF-2 [6].

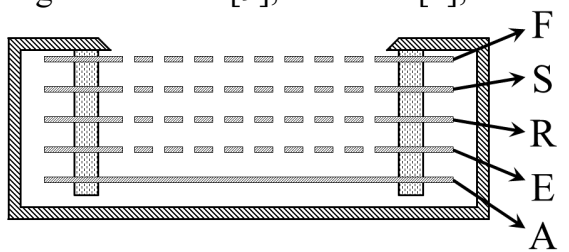

F: Floating potential shield grid (bounds plasma)

S: Screen grid (rejects electrons)

R: Retarding grid (rejects ions $<$ variable energy)

E: Electron suppression grid

A: Anode (collects ion current)

Figure 4. Retarding Potential Analyzer (RPA)

The Erosion Sensor directly (derives flight heritage from AEHF-2 [6]) measures the loss of conductive material from its surface. It consists of a serpentine layout of a gold conductive trace on a silicon wafer and a temperature transducer. The PDP-E measures the resistance of the gold trace and the temperature.

The Photometer measures the effects of thruster plume exposure on optical materials. It contains a pair of identical photodiodes positioned behind identical thin film glass filters. One filter is installed with the thin film exposed to space, and the other is installed with the glass surface exposed to space. The photodiodes collect light from the Sun, which may increase or decrease over time as the optical surface is eroded or other spacecraft materials are deposited. A temperature transducer is also included. The PDP-E reverse biases both photodiodes and measures the photocurrent and temperature. This type of Photometer has flight heritage with several USAF missions [1], [6], [11].

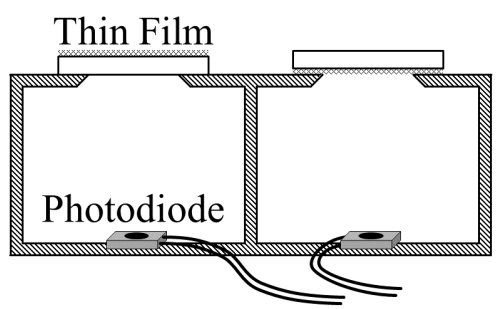

Figure 5. Photometer

The Radiometer measures the long term effect of plasma exposure on spacecraft thermal control surface treatments. It utilizes two temperature transducers to monitor the thermal state of the exposed surface and the baseplate. The PDP-E monitors both temperatures. Radiometers of this type have flight heritage with several USAF missions including ESEX, TacSat-2, AEHF-2 [1], [6], [11]. 


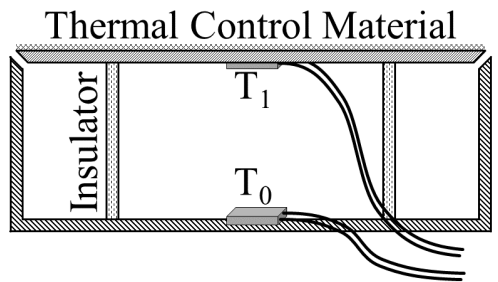

Figure 6. Radiometer

The Solar Cell exhibits an I-V curve behavior which varies over temperature and which evolves over its life when the cell is illuminated. A temperature transducer is included to factor out the contribution from cell temperature. The PDP-E measures the I-V curve and monitors the temperature. The specific type of solar cell would be a matched version (single element) to the ARRM main solar arrays. Diagnostic inflight solar cell elements have flown on ESEX [1], TacSat-2 [11], and AEHF-2 [6].

\section{Sensor Signals}

Table 1 shows the signal specifications for the planned PDP sensor suite. Ranges and maximum resolutions for the different sensor types are given, both for control signals (driver outputs) and sense signals (data inputs).

\section{Arrangement}

In the reference approach, two copies of the PDP-E were to be mounted internal to the bus near the thrusters. A notional concept was for each to address 4 RPAs, 4 Flux Sensors, 4 Planar Langmuir probes, 4 Erosion Sensors, 4 Photometers, 2 Ion Fast Probes, and 4 Radiometers; and would include channels to digitize data from 2 PPU fast discharge current sensors. The sensor distribution around the spacecraft bus was not finally determined. One approach would have been to mount all the sensors for each PDP-E to a monolithic "tower" that would be relatively simple to integrate, and the two towers would provide some position and angle diversity. Another approach would have been to distribute the sensors more evenly over the spacecraft, requiring more complex integration but providing relatively good diversity of measurement sites. For the solar array sensors, two modified PDP-E assemblies (with measurement ranges tailored to signal levels expected at the array locations, and without the fast probe capability), would be mounted to each array, likely on the array boom structure. Each array PDP-E would control 3 RPAs, 3 Flux Sensors, 3 Planar Langmuir probes, 3 Erosion Sensors, and 3 Solar Cells.

\section{IMPLEMENTATION STRATEGY}

\section{Sensors}

For the reference approach, existing sensor designs were used. PDP sensors were to be built at JPL; differences between the previously-experienced earth-orbit environment and those to be encountered in deep space would have required review and likely minor re-design and qualification for some sensors. Electronics local to sensors (such as circuits required to supply the functions of transimpedance buffering or the more sophisticated high rate analog-to-digital conversion inside the Fast Probes) were to be acquired the electronics contracts as described below.

\section{Electronics}

Early in the project, the PDP-E electronics assembly was identified to be the longest lead development for the PDP subsystem, and a large portion of the initial effort was focused in that direction. Measurement of small currents at large potentials is of particular difficulty, requiring a designer skill set that is in relatively short supply. To minimize project startup time and staffing, the decision was made to gather information and encourage vendor interest via the use of preliminary study contracts for a preliminary technical approach for providing the PDP-E units. The PDP team had prepared materials (statement of work, justification, specimen subcontract) for these studies. The results of the study contracts would provide confidence both to the project and to the PDP team that an appropriate balance could be struck between engineering rigor and economy when carrying out the subsequent contract procurement for the various PDP-E units.

The scope of work for the PDP-E study was to include a basic technical framework for the PDP electronic sensor drivers, control, data acquisition, and command \& data handling subsystem. The work was to include consideration of project and environmental qualification levels, consistency of assumed development risk with project objectives, and assessment of suitable classes of components. Vendors were to deliver documentation of the basic approach, interface and resource requirements, environmental requirements, and performance estimates. Forecasts of the cost and schedule for the detailed design, build, and testing of the PDP-E assemblies were to be provided. Detailed design and further hardware were not to be included in the scope of work. Acquisition of the flight PDP-E units, was to be executed by a subsequent contracting activity for detailed design, development, and build of engineering model (EM) and flight model (FM) hardware. The flight build acquisition was not intended to formally follow on from the studies; instead, the project and PDP team intended to use the studies' outcomes to inform, rather than determine, the flight PDP-E acquisition process.

\section{Flight Qualification}

Sensors selected for the PDP reference configuration have significant laboratory test histories and project-appropriate qualification testing, as well as flight heritage and history. However, none were qualified to the stringent engineering standards typically employed in NASA deep-space missions. Further, the flight environments of these sensors were variously low Earth orbit to geosynchronous Earth orbit, not interplanetary space. These limitations were planned to be considered in light the ARRM mission's risk posture. On the one hand, proper operation of the PDP was programmatically deemed non-critical to the ARRM flight system mission 
Table 1. Control Signal and Sense Signal Specification

\begin{tabular}{|c|c|c|c|c|}
\hline Sensor & Control Signal & $\begin{array}{l}\text { Maximum } \\
\text { Resolution }\end{array}$ & $\begin{array}{l}\text { Full Scale Sense } \\
\text { Signal Range(s) }\end{array}$ & $\begin{array}{l}\text { Maximum } \\
\text { Resolution }\end{array}$ \\
\hline RPA & $\begin{array}{c}\text { Retarding grid } \\
0 \text { to } 1 \mathrm{kV}, 1 \mathrm{~mA} \\
\text { adjustable rate }>10 \mathrm{~V} / \mathrm{s}^{*}\end{array}$ & $0.5 \mathrm{~V}$ & $\begin{array}{c}{[0 \text { to } 100 \mathrm{nA}]} \\
{[0 \text { to } 10 \mathrm{uA}]}\end{array}$ & $\begin{array}{l}{[10 \mathrm{pA}]} \\
{[1 \mathrm{nA}]}\end{array}$ \\
\hline Flux Sensor & $\begin{array}{c}\text { Anode: }-50 \text { to }+200 \mathrm{~V} \\
\text { adjustable rate }>10 \mathrm{~V} / \mathrm{s}^{*}\end{array}$ & $0.1 \mathrm{~V}$ & $\begin{array}{l}{[0 \text { to } 1 \mathrm{uA}]} \\
{[0 \text { to } 10 \mathrm{uA}]}\end{array}$ & $\begin{array}{c}{[100 \mathrm{pA}]} \\
{[1 \mathrm{nA}]} \\
\end{array}$ \\
\hline Planar Langmuir & $\begin{array}{c}\text { Anode \& Guard bias } \\
-200 \text { to }+200 \mathrm{~V}, 20 \mathrm{~mA} \\
\text { adjustable rate }>10 \mathrm{~V} / \mathrm{s}^{*}\end{array}$ & $0.1 \mathrm{~V}$ & $\begin{array}{l}{[ \pm 20 \mathrm{~mA}]} \\
{[ \pm 10 \mathrm{uA}]}\end{array}$ & $\begin{array}{l}{[2 \mathrm{uA}]} \\
{[1 \mathrm{nA}]}\end{array}$ \\
\hline Erosion Sensor & $\begin{array}{l}\text { Sensor trace DC stimulus } \\
\text { (as needed) }\end{array}$ & N/A & $\begin{array}{l}\text { R: } 50 \text { ohm to } 10 \mathrm{kohm} \\
\text { T: }-100 \text { to }+150 \text { range }\end{array}$ & $\begin{array}{c}1 \% \\
{[1 \operatorname{deg} \mathrm{C}]}\end{array}$ \\
\hline Photometer & $\begin{array}{l}10 \mathrm{VDC}, 2 \mathrm{~mA} \\
\text { reverse bias }\end{array}$ & $\mathrm{N} / \mathrm{A}$ & 0 to $500 \mathrm{uA}$ & $100 \mathrm{nA}$ \\
\hline $\begin{array}{l}\text { Fast Probe: PPU } \\
\text { Discharge }\end{array}$ & $\mathrm{N} / \mathrm{A}$ & N/A & $\pm 2.5 \mathrm{~V}, 1 \mathrm{MHz}$ & $\begin{array}{c}{[100 \mathrm{nA}]} \\
{[1 \mathrm{us}]}\end{array}$ \\
\hline $\begin{array}{l}\text { Fast Probe: HET } \\
\text { plasma plume }\end{array}$ & $\begin{array}{l}-100 \text { to }+100 \mathrm{~V} \\
\text { detector bias }\end{array}$ & $0.1 \mathrm{~V}$ & $\begin{array}{l}{[ \pm 20 \mathrm{~mA}], 1 \mathrm{MHz}} \\
{[ \pm 500 \mathrm{uA}], 1 \mathrm{MHz}}\end{array}$ & $\begin{array}{c}{[2 \mathrm{uA}]} \\
{[50 \mathrm{nA}]}\end{array}$ \\
\hline Radiometer & $10 \mathrm{VDC}, 2 \mathrm{~mA}$ & & 0 to $500 \mathrm{uA}$ & $50 \mathrm{nA}$ \\
\hline Solar Cell & $\begin{array}{l}\text { As needed to measure solar cell } \\
\text { I-V curve }\end{array}$ & N/A & $\begin{array}{l}0-5 \mathrm{~V} \\
0-2 \mathrm{~A}\end{array}$ & {$[1 \%]$} \\
\hline
\end{tabular}

success criteria; on the other hand, the extensibility requirements would not have been met if the PDP did not meet some minimum success criteria. In this development environment, the PDP team and project assessed risks were assessed informally from the perspective of a technology development mission, within the ARRM mission assurance framework. Formal risk assessment and qualification decisions were to be undertaken later in the ARRM project, and would have been in line with the moderate risk posture accepted for the PDP system.

\section{A-Team Study Methodology}

A-team studies, hosted by the the JPL Innovation Foundry, are flexible, innovative, and informal facilitated group discussions typically intended to help a formulation phase effort advance its degree of conceptual maturity [12]. In the case of the PDP, the client (the PDP delivery team) was looking for confirmation from the plasma environments community that the planned concept approach (the reference configuration discussed above) was complete, valid, and compellingly valuable to the host technology mission. The client was also looking for innovative plasma measurement or sensor approaches not considered before that were known to one or more of the subject-matter expert (SME) assembled community. Finally, the client asked the assembled experts to discuss, review, and recommend the potential value and efficacy of various sensors and measurements, whether previously considered or not, outside of the reference configuration.
The intent of the client team was to review the reference configuration in light of the A-team study results, and implement changes as needed to most efficiently and completely meet the host's extensibility requirements for future missions. The team recognized that a possible outcome of the study would be A-team recommendations to develop new or improved sensor or measurement technology. Recognizing chronically tight resources, the client team planned to trade development benefits against available resources, select key technologies to be pursued, and make selected technology development recommendations for implementation and inclusion on the flight PDP system.

The PDP A-team study was convened over a two-day period at the end of February 2017. Six PDP team members participated, as did 20 thruster and space plasma experts from NASA and AFRL, along with a technical representative from the ARRM electric propulsion subsystem contractor. Over the sessions during the two days, the group worked well together with an informal and collaborative atmosphere encouraged by the A-team facilitators. The external participants expressed enthusiasm for the idea of plasma diagnostics aboard the mission. One one hand, they provided confirmation of the essential value of the reference configuration; on the other, they expressed many new ideas for sensors, configurations, and measurement types to add value beyond the baseline configuration. 


\section{A-TeAm Results ANd FindingS}

The A-team approach was structured to provide a diversity of inputs to both assess the sufficiency of the PDP reference and to identify sensor enhancements or new measurements (and their associated sensors) that would substantially improve the PDP's contribution to maturation and development new highpower SEP systems.

Four functionally derived aspects of the induced environment and effects were identified as topic areas to reflect the involved spacecraft systems and their interactions with EP devices: Thruster Dynamics, Array-specific Effects and Environments, Plasma Induced Environmental Effects, and Thruster Plume Energetic Particle Content. The two days of in-depth technical back-and-forth on the admittedly overlapping aspects created a large volume of raw material including masses of presented material and seeming acres of whiteboard writings generated during the hours of discussion and small group information synthesis. This section summarizes the key findings reached by the A-team. The collective input from the A-team participants provided a crucial solidification or technical consensus on the way forward in developing a PDP that fully realizes its fundamental goal of extensibility of high power Hall thruster technology. A wide array of plausible spacecraft sensors and approaches were evaluated along with the impact or effectiveness of the measurements possible. A detailed discussion of the proceedings of the study follows.
To summarize the study results, the A-team group determined the current reference approach to be largely satisfactory with respect to the extensibility requirement. A few shortcomings of the reference approach were noted, mostly where the heritage sensor designs did not match well with the larger scale of the spacecraft and mission compared to those of previous flights, or where newly-developed lab measurement techniques would provide large extensibility returns with modest investments in sensor development.

\section{Thruster Dynamics}

The role of the PDP in assessing the topic of Thruster Dynamics was presented to the A-team with three general questions:

(1) What changes of significance occur to thrusters over their life, considering both slow (hours, weeks, years) processes associated with thruster cycling and wear, as well as fast plasma oscillations or instabilities $(\mathrm{kHz}$ to $\mathrm{MHz}$ ?

(2) How can flight diagnostic measurements contribute to our general understanding of thruster life limiting processes?

(3) What effects or degradation can be observed on solar arrays associated with thrusters on a deep space mission?

Table 2. A-team study subtopic voting for selected Thruster Dynamics specific questions

\begin{tabular}{|c|c|c|c|c|}
\hline Subtopics for Thruster Dynamics: & Favorite & $\begin{array}{l}\text { Most } \\
\text { compelling }\end{array}$ & $\begin{array}{c}\text { Low- } \\
\text { hanging } \\
\text { fruit }\end{array}$ & $\begin{array}{c}\text { PDP } \\
\text { reference } \\
\text { applicability }\end{array}$ \\
\hline Plasma processes: location of ionization zone, plasma potential variations in time and space & Some & Many & None & Good \\
\hline Plasma oscillations & Many & Few & Some & Yes \\
\hline Ion energy distribution (IEDF) and angular dependence & Many & Few & None & Good \\
\hline Validation of thruster design approach: center cathode, mag. shielding, etc. & Few & Many & None & Some* \\
\hline Validation of thermal model: plasma load, location/shifting of load with time, emittance, etc. & None & None & Many & No* \\
\hline Ground chamber effects: conducting walls, pressure, electrical differences & Some & Some & None & Some* \\
\hline Flow rate vs. discharge current & None & None & Many & No* \\
\hline $\begin{array}{l}\text { Validation of HERMeS design mitigating many ground-to-space differences (central cath., } \\
\text { etc.) }\end{array}$ & Few & Few & Few & Some* \\
\hline Understanding pole erosion: cathode dependence, species dependence, etc. & Some & Few & None & Some* \\
\hline Low-energy ions and IEDF variation with thruster operation and sputtering impact & None & None & Many & Yes \\
\hline Spot-plume transition point for cathode & Few & None & Few & No \\
\hline Correlations between different measurements & Few & None & None & Some \\
\hline Thruster spacing/interactions (close proximity higher power clusters) \& per thruster variances & None & Few & None & Some \\
\hline Where can one safely position higher-power solar arrays & None & Few & None & Yes \\
\hline Return of thrusters (or pole covers) after mission and take photographs & Few & None & None & No \\
\hline Cathode sharing by multiple thrusters & None & None & Few & Good \\
\hline Solar cells: return of sample, photos of arrays, arcing rate/energy on arrays, thruster influence & None & None & Few & No \\
\hline * applicable data obtained in ground test or in flight thruster telemetry & & & & \\
\hline
\end{tabular}


The overarching theme that these questions were framed within was the orders-of-magnitude difference between ground testing (typically $10^{-6}$ torr) and the space environment (typically $<10^{-11}$ torr). In response to these fundamental questions, the A-team participants then assembled and informally (and publicly) voted in the categories "favorite", "most compelling", and "low-hanging fruit" on the list of Thruster Dynamics subtopics presented in Table 2, together with the PDP team's estimation, in the final column, of whether the PDP reference configuration addresses the subtopic. The table is vertically ranked with subtopics receiving many votes at the top, and observation of the voting trends provides insight into the community view of the relative importance of each subtopic. A good correlation between highly voted subtopics with the planned PDP reference capability provides a measure of validation for the PDP approach in this topic. Asterisked fields represent subtopics that are substantially covered by measurements other than those to be provided by the PDP.

The top ranked subtopics for Thruster Dynamics include methods of measuring plasma processes, properties, and oscillations as well as validating thruster system design models. Each of the remaining subtopics were of interest to only one or two SMEs and-while not to be neglectedshould be viewed with lower overall priority for inclusion in the PDP system goals. One recurrent subtopic that exists for Thruster Dynamics (and for the remaining topics of Arrayspecific Effects and Environments, Plasma Induced Environmental Effects, and Thruster Plume Energetic Particle Content) is the ion energy distribution function (IEDF). IEDFs were voted to be the single most important metric of Thruster Dynamics. Energetic ions provide both the propulsive force of EP devices and are the main mechanism for erosion and sputtering of the thruster and spacecraft, thereby warranting higher importance for scrutiny by the in-flight diagnostic capability of the PDP. This finding is a good sanity check on the A-team approach, as it turns out. Nearly every instrumented EP spacecraft flown has similarly emphasized IEDF measurements, as demonstrated by the inclusion of IEDF instruments on Express A [2], SMART-1 [5], DS1 [9], TacSat-2 [10], and AEHF-2 [6]. Overall, while the A-team had some ideas for future improvements of dynamics sensors, they endorsed the existing sensor complement. One specific recommendation made by some participants was to include high-speed optical sensors to augment the fast particle and current sensors already to be manifested. More discussion of optical sensors are provided below.

\section{Array-specific Effects and Environments}

The role of the PDP in evaluating the topic of Array-specific Effects and Environments was presented to the A-team within the context of two general questions:

(1) How do ion velocity distributions change between ground test and space flight?

(2) What thruster/spacecraft erosion is associated with the plasma plume, where on the spacecraft do erosion products go, and is it enough to be an engineering threat?

The overall theme of these identified subtopics was to validate and inform plume/spacecraft interaction models. As with the prior topic, IEDFs again earn high marks in terms of overall consensus (see Table 3). However, the A-team identified the overall most important areas to investigate for Array-specific Effects to be erosion- and deposition-specific effects. The relative weight associated to erosion and deposition processes is driven by the incapacity of ground test facilities to meaningfully test the deposition environment imposed by a multi-thruster high-power EP subsystem (without being swamped by deposition from sputtered chamber surfaces), or to accommodate an overall, thruster-on system integrated ground test of the ARRM spacecraft with tens of $\mathrm{kW}$ of solar panels. The resulting reliance on spacecraft interaction models to estimate the erosion and deposition arising from thruster operation requires in-flight validation to facilitate the extension of these tools to the design of higher power SEP systems. A number of subtopic array specific recommendations from the A-team strongly and expressly relate to the plasma currents between the thruster, cathode, spacecraft, and arrays, and that instruments and means of achieving these goals should also be prioritized.

Table 3. A-team Study Subtopics for Selected ArraySpecific Effects and Environments Questions.

\begin{tabular}{|c|c|}
\hline $\begin{array}{l}\text { Subtopics for Array-specific Effects and } \\
\text { Environments }\end{array}$ & $\begin{array}{c}\text { PDP } \\
\text { reference } \\
\text { applicability }\end{array}$ \\
\hline Ion energy distribution at the arrays & Good \\
\hline Plasma potentials at the arrays & Good \\
\hline $\begin{array}{l}\text { Electron temperature and array sheath potential at } \\
\text { multiple array locations }\end{array}$ & Good \\
\hline Increased number of PDP sensors & $\mathrm{No}^{\wedge}$ \\
\hline $\begin{array}{l}\text { Data with thrusters off as well as with only cathodes } \\
\text { on }\end{array}$ & Yes \\
\hline $\begin{array}{l}\text { Identify locations where coatings (thermal, anti- } \\
\text { reflective, etc.) are eroded over mission }\end{array}$ & Good \\
\hline Solar wind kinetic energy & Some \\
\hline Wear on solar cell interconnects & Some \\
\hline Validate models of both low- and high-energy ions & Yes \\
\hline Cathode common potential variations & Good \\
\hline $\begin{array}{l}\text { Validation of extensibility of thruster body grounding } \\
\text { to cathode common \& central cathode }\end{array}$ & Good \\
\hline
\end{tabular}

Another observation and recommendation from the A-team was that the inclusion of sensors on the solar panel wings is essential and that four or more probe locations per wing is optimal. Early thruster-spacecraft interaction analysis using the NASPAS (NASA Spacecraft-Plume Analysis Software) and HallPlume2D tools under development [13], [14], has indicated many orders of magnitude differences in plasma parameters across the solar wings, as seen in Figure 7. The resulting large variation in deposition and erosion process across the wings would thus require array-distributed sensor packages for validation as noted in the value of adding an increased number of PDP sensors beyond the reference configuration. The PDP take-away from this discussion has 
sparked ideas for two sensor developments - one in lightweight versions of erosion/deposition sensors for flexible array mounting, and another for ion flux sensors with even less entry-angle dependence (based on the very wide distribution of entry angles to sensors on the sun-tracking arrays). These are discussed more fully below.

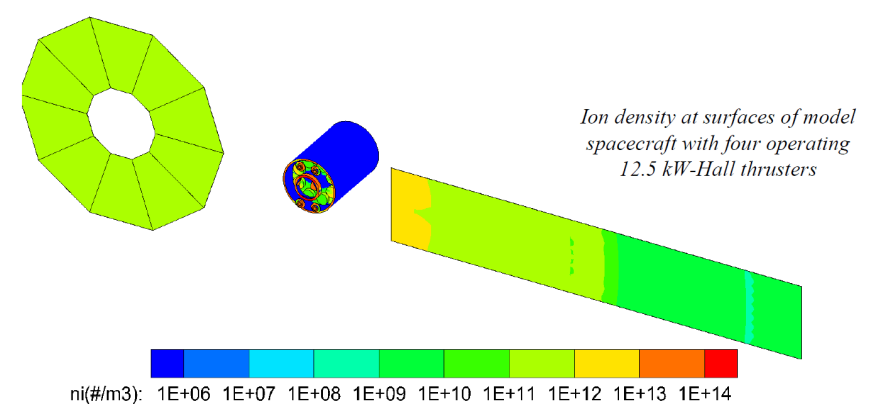

Figure 7. Sample early NASPAS simulation of far-field plasma interaction with two early conceptual $40-\mathrm{kW}$ SEP spacecraft configurations from Ref. [14].

\section{Plasma Induced Environmental Effects}

The role of the PDP in considering the topic of Plasma Induced Environmental Effects was presented to the A-team framed by three basic motivations:

(1) Do our plume/spacecraft interaction predict the observed effects?

(2) Is the physics behind our low- and high-energy ion source models sufficient to capture observed phenomena?

(3) Can we confirm that array currents relate to the thruster body potential management system as expected?
The common theme that these points encompass are measurements that would confirm and improve future models of the plasma-induced spacecraft environment. In Table 4, the A-team generated a list of subtopics for addressing Plasma Induced Environmental Effects, with category voting to help in ranking. However the list reveals - yet again - the value placed on IEDF data. Other recurrent subtopics address the plasma properties and erosion at various spacecraft surfaces.

Finally, it's interesting to note that the A-team was enthusiastic about the PDP's added-value capability to measure how the asteroid environment affects the solar wind, and also to sense thruster/asteroid interactions in the areas of dust or sputtered material.

\section{Thruster Plume Energetic Particle Content}

The role of the PDP in assessing the topic of Thruster Plume Energetic Particle Content was presented to the A-team within the framework of a single goal:

(1) Can the physics and predictions of plume and spacecraft interaction models be validated with these flight measurements?

The A-team deliberations revealed (as might have been expected) the central importance of the IEDF in reaching this goal. Table 5 lists the series of subtopics the A-team identified for addressing Thruster Plume Energetic Particle Content.

Table 4. A-team Subtopics for Selected Plasma Induced Environmental Effects Issues.

\begin{tabular}{|c|c|c|c|c|}
\hline Subtopics for Plasma-induced Effects & Favorite & $\begin{array}{c}\text { Most } \\
\text { compelling }\end{array}$ & $\begin{array}{c}\text { Low- } \\
\text { hanging } \\
\text { fruit }\end{array}$ & $\begin{array}{c}\text { PDP } \\
\text { reference } \\
\text { applicability }\end{array}$ \\
\hline Energy spectrum of charged particles impacting spacecraft with thruster operating & Some & Many & Few & Good \\
\hline Dust collection and mitigation (proximity operations; boulder collection) & Many & Many & None & Some $^{\wedge}$ \\
\hline Momentum transfer (impingement) & None & None & Many & No* \\
\hline Composition of deposited material & Many & Some & None & Some \\
\hline Deposition rates & Many & Few & None & Good \\
\hline Erosion & None & Few & Many & Good \\
\hline Spacecraft potential & Few & None & Some & Yes \\
\hline Asteroid material re-deposition (gravity tractor demo phase) & Many & None & None & Good $^{\wedge}$ \\
\hline Ambient space environment (with vs. without thruster operating) & Few & Few & None & Good \\
\hline Impact of plasma plume on data link telecommunication capabilities/throughput & Few & None & Few & No* \\
\hline Solar wind up to $5 \mathrm{keV}$ & Few & None & None & Some $^{\wedge}$ \\
\hline Thermal loads & None & None & Few & Yes \\
\hline Surface properties & None & None & Few & Some \\
\hline \multicolumn{5}{|l|}{${ }^{\wedge}$ not a project objective for the PDP reference configuration } \\
\hline * applicable data obtained in ground test or in flight thruster telemetry & & & & \\
\hline
\end{tabular}


These subtopics possess significant overlap with the prior three topic evaluations, but additional details on IEDFs are proposed such as: increased temporal resolution $(\mathrm{kHz}$ to $\mathrm{MHz}$ ), methods of obtaining distributions at multiple angles from the thrust axis, improved ion sputtering libraries, and charge state sensitive measurements. Optical emission spectroscopic sensors was also an included as a new subtopic and an A-team recommendation for the PDP that could provide insight into both the electron and ion energy distributions, and would have substantial cross-topic impact.

\section{Table 5. A-team subtopics for examining Thruster Plume Energetic Particle Content}

\begin{tabular}{|c|c|}
\hline $\begin{array}{l}\text { Subtopics for Thruster Plume Energetic Particle } \\
\text { Content }\end{array}$ & $\begin{array}{c}\text { PDP } \\
\text { reference } \\
\text { applicability }\end{array}$ \\
\hline $\begin{array}{l}\text { Measurement of IEDF including higher charge state } \\
\text { ion distributions }\end{array}$ & Good \\
\hline $\begin{array}{l}\text { Spacecraft configurations that avoid/minimize } \\
\text { sputtering by thruster plume }\end{array}$ & Good \\
\hline $\begin{array}{l}\text { Validation of erosion of docking adapter (relocation } \\
\text { of thrusters) }\end{array}$ & Yes \\
\hline $\begin{array}{l}\text { Shrink uncertainties: modeling, sputter yield (angular, } \\
\text { species, and density dependences) }\end{array}$ & Good \\
\hline $\begin{array}{l}\text { Validation of thruster and cathode erosion/life models } \\
\text { (pole covers, etc.) }\end{array}$ & Some \\
\hline Current density measurements & Yes \\
\hline $\begin{array}{l}\text { Optical emission measurements: photons from } \\
\text { neutrals/singles/doubles/triples }\end{array}$ & $\mathrm{No}^{\wedge}$ \\
\hline Plasma potential measurements & Yes \\
\hline Particle velocity vector measurements & Some \\
\hline Direct erosion measurements & $\mathrm{No}^{\wedge}$ \\
\hline High-voltage RPA for $1 \mathrm{keV} / \mathrm{q}$ IEDF measurements & $\mathrm{No}^{\wedge}$ \\
\hline $\begin{array}{l}\text { Wider acceptance angle flux probe for coarser IEDF } \\
\text { measurements }\end{array}$ & $\mathrm{No}^{\wedge}$ \\
\hline Time-resolved (kHz to MHz) RPA based IEDFs & $\mathrm{No}^{\wedge}$ \\
\hline Increased number of PDP sensors & $\mathrm{No}^{\wedge}$ \\
\hline IEDF at angles less than $90^{\circ}$ (or $70^{\circ}$ ) off-thruster axis & Some \\
\hline Enhanced sputtering libraries & $\mathrm{No}^{\wedge}$ \\
\hline Enhanced optical emission spectroscopy models & $\mathrm{No}^{\wedge}$ \\
\hline Thruster gimbaling towards PDP & Some $^{\wedge}$ \\
\hline Sacrificial instrumented CubeSat & No \\
\hline
\end{tabular}

The key challenge identified with examining Thruster Plume Energetic Particle Content is, again, the orders-of-magnitude differences between conditions encountered in ground tests and in space, particularly for the back-flow and far-field regions from the thruster. In ground facilities, the far-field ion mean-free-path is on the order of meters, or less; while in flight this rises to kilometers or more [6]. Driven by the inability to test in ground facilities at flight-like background pressures, the resultant ground test ion-neutral collisions inevitably distort the far-field IEDFs by over-enhancing the low-energy ion component. The PDP reference configuration includes several sensors to provide ion velocity information, and A-team members were enthusiastic about discussing sensors with even higher degrees of resolution or sensitivity than in the PDP reference configuration.
PDP Instruments and Sensors as SoA, Enhancing, Enabling, and Breakthrough

The four topics investigated in depth by the A-team provoked the discussion of a wide field of possible, plausible PDP sensors categorized as state-of-the-art (SoA, and included in the reference configuration), enhancing, enabling, and breakthrough (these last three are outside of the scope of the PDP reference configuration). A full list of these identified diagnostics is included in Table 6.

Table 6. A-team identified instruments list.

\begin{tabular}{|c|c|c|}
\hline & Instrument & Measurement \\
\hline \multirow{8}{*}{ 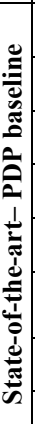 } & Fast Faraday probe & Current density, $j(t)$ \\
\hline & Fast discharge current sensing & Discharge current, $I_{d}(t)$ \\
\hline & Retarding potential analyzer & IEDF \\
\hline & Erosion photometer & erosion, deposition \\
\hline & Resistive erosion sensor & erosion \\
\hline & Langmuir probe & $\begin{array}{l}\text { plasma } \\
\text { density/temp./potential }\end{array}$ \\
\hline & Ion flux probe & IEDF \\
\hline & Radiometer & emissivity/abs. \\
\hline \multirow{8}{*}{ 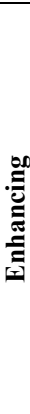 } & Time-resolved IEDF probe & $\operatorname{IEDF}(\mathrm{t})$ \\
\hline & Articulating probe boom & spatial variation of any meas. \\
\hline & Optical emission spectroscopy & plasma density and temp. \\
\hline & Quartz Crystal Microbalance & erosion, deposition \\
\hline & Increased $\mathrm{S} / \mathrm{C}$ instrument sites & spatial variation of any meas. \\
\hline & Camera (visible light) & depos., erosion, plume prof. \\
\hline & Thermal imaging camera & temperature profiles \\
\hline & Time-resolved int. thruster LIF & $\operatorname{IEDF}(\mathrm{t})$ \\
\hline \multirow{6}{*}{ 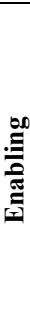 } & Time-resolved OES & $\begin{array}{l}\text { time-resolved plasma } \\
\text { fluctuations }\end{array}$ \\
\hline & $\mathrm{E} \times \mathrm{B}$ Wien filter & IEDF \\
\hline & Ion energy spectrometer & IEDF \\
\hline & Resistive deposition sensor & deposition \\
\hline & Species sensitive depos. sensor & deposition \\
\hline & Thruster gimbaling toward PDP & spatial diversity of any sensor \\
\hline \multirow{6}{*}{ 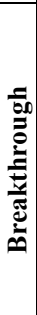 } & Laser induced fluorescence & IEDF \\
\hline & Tandem $\mathrm{E} \times \mathrm{B}+\mathrm{ESA}$ & IEDF \\
\hline & $\begin{array}{l}\text { Molecular species analyzer } \\
\text { (RGA) }\end{array}$ & $\begin{array}{l}\text { universal species } \\
\text { identification }\end{array}$ \\
\hline & In-flight SEM & erosion, deposition \\
\hline & Astronaut collecting sample & erosion, deposition \\
\hline & Sacrificial CubeSat probe & spatial diversity of any sensor \\
\hline
\end{tabular}

The four categories included provide an estimate of the varying degrees of impact these instruments could have in meeting the PDP mission objective of extensibility. However, these categories exclude the challenges many of these instruments have due to: complexity, required 
technology development, mass, power, and cost. These constraints can be used to temper the "effectiveness" of each of these instruments as is discussed in the following Discussion and Analysis Section.

\section{A-team Overall Assessment and Recommendations}

The consensus of the A-team participants was that measurements made by the PDP make a substantial and compelling contribution to validation of plume and spacecraft interaction models (see Table 7 and overview of SEP design model architecture in Figure 8). In addition, the A-team also recognized that the PDP sensors provide substantial flight verification of thruster plasma physics and thermal models. The A-team consensus was that at least the PDP reference instrumentation should be included with ARRM and further, indicated that a PDP-like capability should be given serious consideration for other SEP system new technology flights to allow a satisfactory evaluation of the system and environments. The A-team did not indicate that there was a way to meet the ARRM extensibility requirement, in terms of the thruster-induced spacecraft environment, without the PDP.

Table 7. SEP technologies and extensibility impacted by PDP

\begin{tabular}{|c|c|}
\hline Impact & Design Feature \\
\hline$\star \star \star \Delta$ & Plume model and spacecraft interaction model \\
\hline$\star \star \star \Delta$ & $\begin{array}{l}\text { Array placement/configuration } \\
\text { - Position relative to thruster, gimbaling, rotations, } \\
\text { feathering } \\
\text { - Avoid penalties assoc. with overly conservative } \\
\text { approaches } \\
\text { - Confidence in margins }\end{array}$ \\
\hline$\star$ & Central cathode \\
\hline$\star$ & $\begin{array}{l}\text { Planetary defense - Gravity tractor environments } \\
\text { - Different thruster configuration } \\
\text { - Backsputter of asteroid to S/C }\end{array}$ \\
\hline$\star$ & $\begin{array}{l}\text { Grounding configuration } \\
\text { - Potential characteristic of Langmuir IV curves will } \\
\text { verify }\end{array}$ \\
\hline$\star$ & $\begin{array}{l}\text { Thruster performance and operational considerations } \\
\text { - Understanding ground vs. in-space behavior/phenomena } \\
\text { - Thruster near-field physics and coupling to discharge } \\
\text { model }\end{array}$ \\
\hline$\star$ & Multi-thruster effects and relative placement \\
\hline is & $\begin{array}{l}\text { Thruster/cathode surfaces throughout mission } \\
\text { - Pole/cover and discharge chamber condition } \\
\text { - Remaining service life at end of ARRM } \\
\end{array}$ \\
\hline it & Thruster thermal model \\
\hline
\end{tabular}

\footnotetext{
Legend:

$\star \star$ is $\quad$ PDP provides principal validation

$\star \quad P D P$ verifies or contributes to validation

is Technology development would allow or add to PDP contribution
}

The role of the PDP in meeting the SEP extensibility goal is tabulated in Table 7 and illustrated in Figure 8. The current JPL/NASA high power SEP design architecture relies on multiple models each with various levels of experimental validation. The end result-an SEP technology demonstration mission - in-turn requires in-flight validation of the entire SEP development process by the PDP to fulfill the extensibility requirement of the mission.

\section{DISCUSSION AND ANALYSIS}

Results from the A-Team study were helpful to validate the value of the Reference design. Moreover, the study pointed towards other technologies that would have a large impact on one or more of the four study topics but that need maturation before they can be used for flight diagnostics. In an attempt to quantify the effectiveness of these diagnostics, a metric was created to express the PDP-team's assessment of the value and feasibility of each of the instruments/approaches from the A-Team study. More specifically, a score from 1 (not important) to 10 (most important) was given, based on an assessment of the topic impact level (TIL) for each instrument/approach on each of the four study topics, which is a quantitative representation of the impact as perceived from the A-Team study. Similarly, an implementation cost factor $(\mathrm{CF})$ score from 1 to 10 was given to each instrument/approach based on an assessment of the effort and spacecraft resources (mass, power, complexity) that it would take to fly/implement each of the proposed instrument/approaches. An approximate technology readiness level (TRL) for each instrument/approach is also supplied to help temper the feasibility ranking. Finally, an overall metric was derived to assess the effectiveness of each concept as follows:

$$
\text { Effectiveness }=\frac{\left.(T R L+1) \cdot T I L\right|_{\max } .}{C F}
$$

The expression above takes the maximum value of the impact score among the four study topics and multiplies it by the TRL divided by the cost factor to obtain an overall metric for our analysis.

Table 8 summarizes the assessment above for each of the diagnostics addressed during the A-Team study. As expected, the reference instruments score very high since they are a set of simple, light, and small sensors targeted to address each of the four topic areas. The table shows other very mature technologies (TRL 9) like Radiometers or Quartz Crystal Microbalance (QCMs) sensors [1] also have a high score, which have overlapping capabilities with some of the Reference design sensors. For example, erosion photometers were selected for the Reference design instead of QCMs based on cost considerations.

Of special interest are those technologies that have a high effectiveness but that need developmental effort before they can be used for flight $(\mathrm{TRL}<7)$. An example are Optical Emission Spectrometers (OES), which could further an understanding of thruster dynamics and plasma induced effects by examining the line intensities associated with 
electron collisions and atomic relaxation processes [15]. Although currently at low TRL $(\approx 5)$, the sensor implementation is straightforward: new ultra-narrowband filters currently available allow individual line intensities to be measured accurately by simply putting a filter in front of a photodiode with a baffle. This simple sensor could be an excellent non-intrusive diagnostic of the electron temperature, which is a key health diagnostic for xenon electric thrusters. The development of this sensor has to go hand in hand with the enhancement of collisional-radiative models (CRM), which are presently under development and evaluation at various institutions [16], [17]. The models would be used to obtain thruster plasma properties from the OES measured line intensities. Analysis and coordination with modelers performing xenon CRM modeling for thrusters will be essential to determine preliminary sensor configurations, including sensor sensitivity as well as instrument angular sensitivity to both filter mount angle and allowable divergence of incident light.

A resistive deposition sensor is another feasible sensor needing some development (TRL $\approx 6$ ) that would have a high impact in the study of array specific and plasma induced effects, as well as on the characterization of energetic particles from the plume. The enhancement of sputtering libraries is another important co-development with this sensor that involves simple materials testing that would largely reduce the uncertainty in the models.

Electrostatic Analyzers (ESA) also score very high in the assessment. These instruments are capable of characterizing the ion spectra at the energies of interest for electric propulsion [18]. Although these sensors have been flown many times as science instruments to study the natural space environment [19], their use as in-flight plasma diagnostics for electric propulsion would require the development of more compact and lightweight sensors as well as sensitive current collection electronics. Similarly but at much lower TRL $(\approx 3)$, $\mathrm{E} \times \mathrm{B}$ Wien filters [20] would also be very helpful to characterize the Ion Energy Distribution Function (IEDF) as a function of propellant charge state but would need significant development efforts to reduce the mass and size of existing instruments so that they can be used in space for electric propulsion plasma diagnostics. The combination of both ESA and $\mathrm{E} \times \mathrm{B}$ sensors would be an excellent diagnostic for IEDF.

Although not discussed during the A-Team study, plasma diagnostics of electric propulsion thrusters would highly benefit from improvements on the energy knowledge and field-of-view properties from retarding potential analyzers (RPA). More specifically, the characterization of the plasma environment around the solar arrays would benefit from retarding potential analyzers agnostic to direction, and a design free of retarding grids could be a solution to this problem. Close to the thruster exit (where the signal is stronger and more directional than at the solar arrays), however, a hemispherical probe could provide more accurate energy measurements instead. These new developments would be easy to implement and would add significant value to RPA measurements.

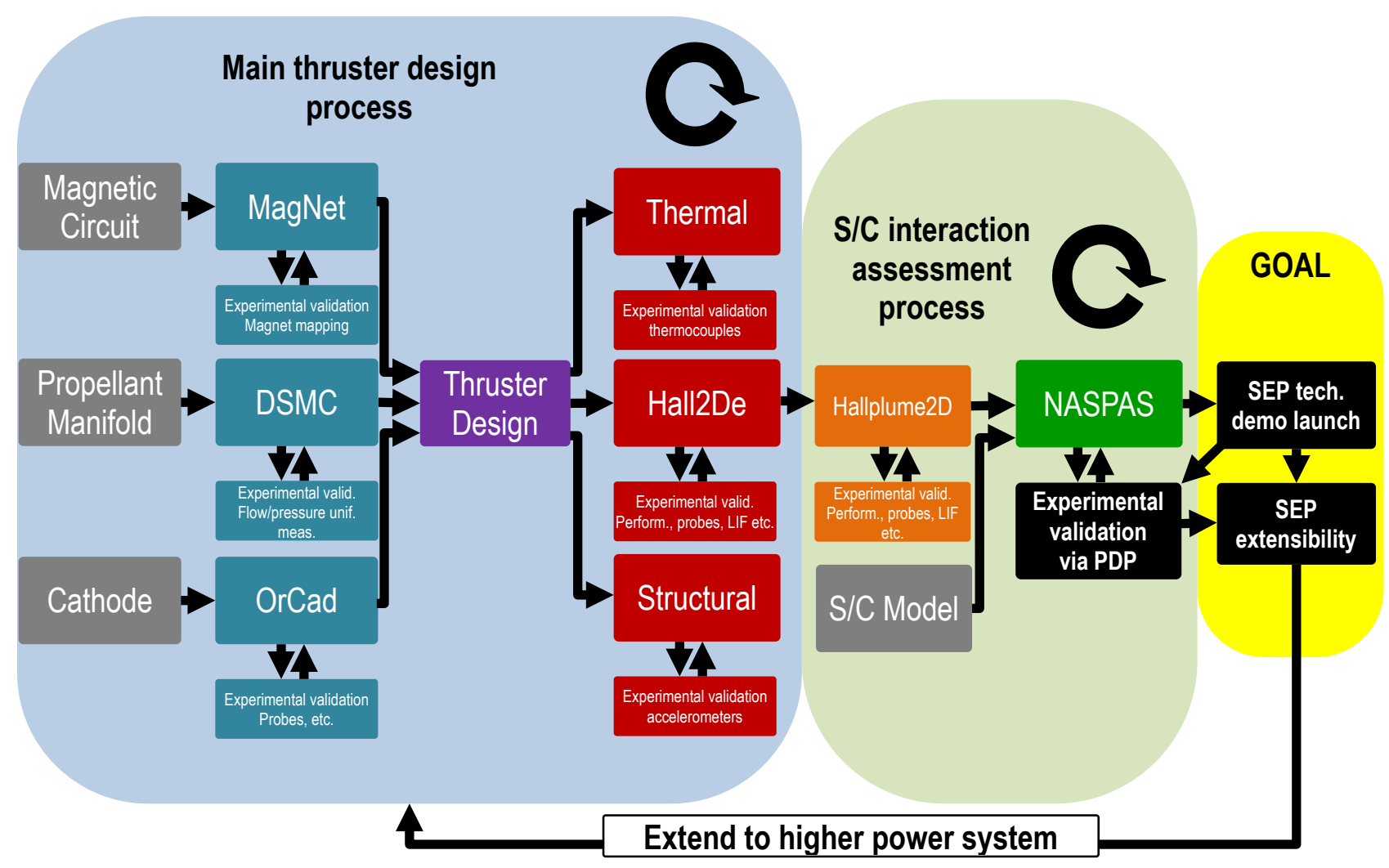

Figure 8. Integral role within thruster design architecture of the PDP in meeting the SEP extensibility goal. 
Table 8. PDP instrument implementation cost, readiness, impact, and effectiveness ranking

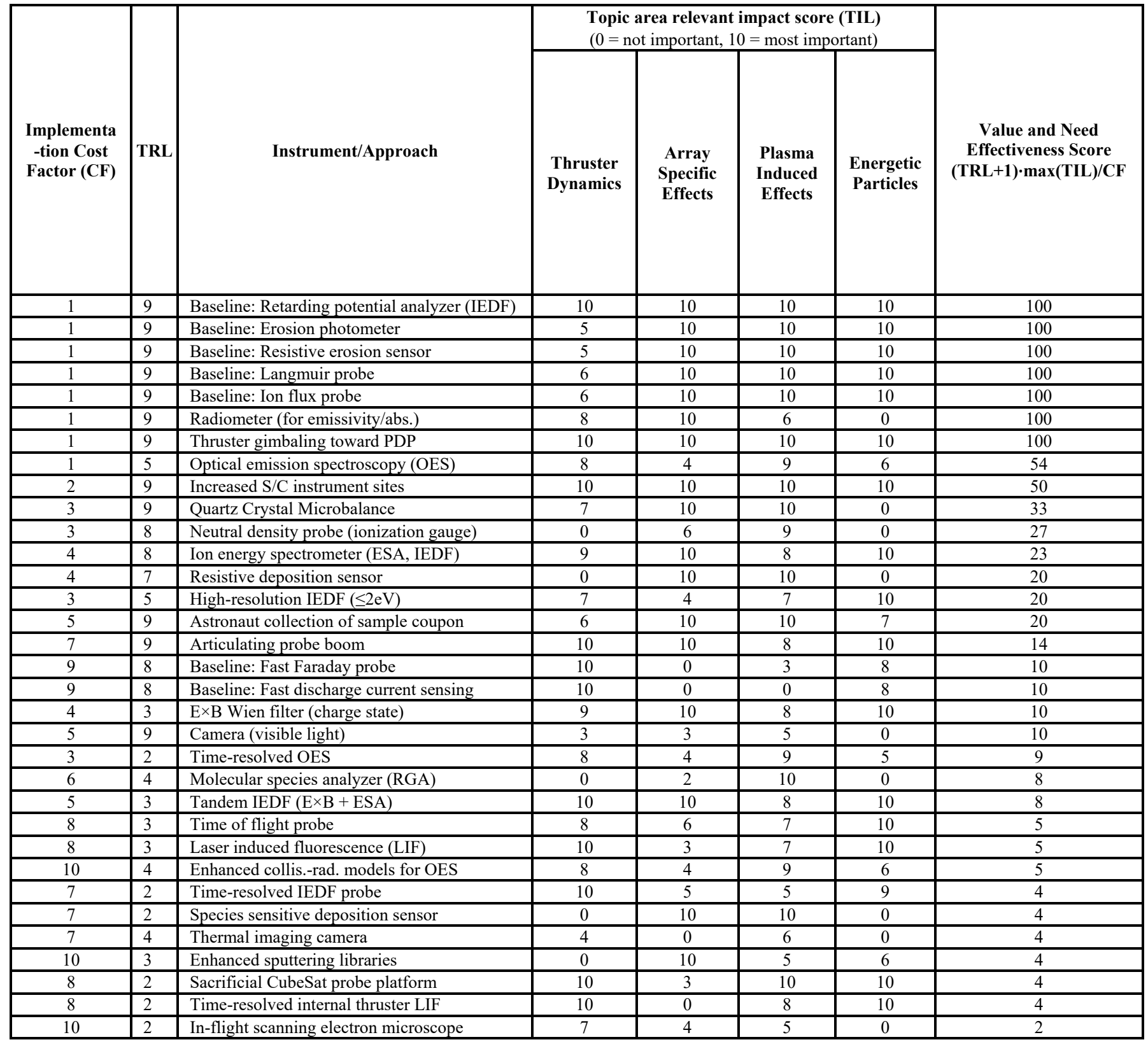

Table 8 also includes a set of high-scoring non-diagnostic approaches that should be considered by future missions including (1) an increase of the number of instruments distributed on the spacecraft, (2) gimbaling the thruster towards the plasma diagnostics sensors, and (3) mounting the sensors on articulating booms. Of special interest to (1) is the development of planar Langmuir probes and ion-energy spectrometers whose interfaces and form resemble those of solar cells so that they can be easily distributed on solar panels. Moreover, the distribution of sensors across the spacecraft would also benefit from the development of wireless communications for space applications (not included in the table), which would relax the harness allocation and reduce the number of physical data interfaces. Gimbaling of the thrusters towards the sensors (2) should be considered a low risk activity by future missions since the capability is already present and it is of large added value to electric propulsion diagnostics. Articulating booms (3) are of high heritage and they would allow better sensor proximity to the thruster plume, but the added complexity and risk that comes with mechanisms and deployables may make this concept difficult to implement. Finally, another concept is the retrieval of sample coupons by astronauts, which would allow direct examination the effect of the thruster plume 
environment on materials, but may be difficult to implement due to astronaut safety measures. The implementation of this approach would likely require modification of the sensor/samples to avoid sharp corners and facilitate their retrieval, and it may likely constrain the location of the samples on the spacecraft to sites away from thruster keepout zones.

Again, it is emphasized that the value of plasma diagnostics in space are tightly coupled to model developmental efforts. As discussed above, in-situ measurements need to be supported by model and library enhancements including sputtering and emission libraries and collision-radiative models. The current JPL/NASA high power SEP design architecture [21] relies on multiple models each with various levels of experimental validation. The in-flight diagnostics above would allow us to further refine and reduce the uncertainty in the models, which is not possible from ground testing due to the background pressure in vacuum chambers and the effect of sputtered ions from the chamber walls.

\section{RECOMMENDATIONS AND CONCLUSION}

The ARRM PDP baseline configuration has been described in relation to project requirements and to a substantively independent review conducted using the informal A-team methods. The significant results validated the fundamental approach and value of the PDP to the host mission concept and its goal of extensibility of the SEP system design to higher propulsion system power. Analysis of the A-team results and recommendations encourages future effort to 1) gimbal the thruster towards the PDP sensors to provide greater position diversity, 2) consider an articulated boom, again for greater diversity, and 3) take advantage of the availability of astronauts, if possible, to return samples for future study. Analysis of the instrument set encourages future consideration of microbalances and other sensitive deposition monitors, and also motivates modest development of 1) lightweighted versions of already-developed plume sensors for integration with flexible solar arrays, 2) modified photometric sensors with line-specific filters to allow plasma characteristics to be optically determined, and 3) re-worked flux sensors, possibly with a hemispherical collectors, to allow distant plasma sensors to have a wider acceptance angle.

\section{ACKNOWLEDGMENTS}

This research was carried out at the Jet Propulsion Laboratory, California Institute of Technology, under a contract with the National Aeronautics and Space Administration. We would like to thank Rosina Cuevas of the JPL Subcontracts Office for her support.

\section{REFERENCES}

[1] G. Spanjers, J. Schilling, S. Engelman, D. Bromaghim, and L. Johnson, "Preliminary analysis of contamination measurements from the ESEX $26 \mathrm{~kW}$ ammonia arcjet flight experiment," in 35th Joint
Propulsion Conference and Exhibit, Los Angeles, CA, 1999, vol. AIAA 99-2709.

[2] D. H. Manzella, R. Jankovsky, F. Elliot, I. Mikellides, G. Jongeward, and D. Allen, "Hall Thruster Plume Measurements On-board the Russian Express Satellites," presented at the 27th International Electric Propulsion Conference, Pasadena, California, USA, 2001, vol. IEPC-2001-044.

[3] C. Scharlemann, M. Tajmar, J. Gonzalez, D. Estublier, G. Noci, and M. Capacci, "Influence of the Solar Arrays on the Floating Potential of SMART-1: Numerical Simulations," in 41st AIAA/ASME/SAE/ASEE Joint Propulsion Conference \& Exhibit, 2005, vol. AIAA 2005-3859.

[4] D. Bromaghim, G. Reed, J. Singleton, D. Connolly, L. Johnson, D. Conroy, R. Gorecki, F. D. Tan, H. Choy, B. Pote, L. T. Byrne, W. J. Connolly, V. H. Hruby, J. K. Barbarits, P. F. Syndey, K. M. Hamada, R. A. Dressler, and Y.-H. Chiu, "Summary of On-Orbit Performance of the 200-W Hall Thruster System on TacSat-2," JANNAF J. Propuls. Energ., vol. 4, no. 1, pp. 87-102, 2011.

[5] M. Tajmar, R. Sedmik, and C. Scharlemann, "Numerical Simulation of SMART-1 Hall-Thruster Plasma Interactions,' J. Propuls. Power, vol. 25, no. 6, pp. 1178-1188, Nov. 2009.

[6] R. B. Lobbia, J. Singleton, D. Brown, J. Blakely, G. Reed, D. Bromaghim, J. W. Koo, M. Scharfe, L. Johnson, and D. Conroy, "Hall Thruster Plume Measurements: AEHF-2 On-Orbit Data, Ground Test Data, and Simulation Results," in JANNAF 9th Modeling and Simulation / 7th Liquid Propulsion / 6th Spacecraft Propulsion Joint Subcommittee Meeting, 2013.

[7] J. H. Gilland, G. Williams, J. M. Burt, and J. Yim, "Carbon Back Sputter Modeling for Hall Thruster Testing," in 52nd AIAA/SAE/ASEE Joint Propulsion Conference, Salt Lake City, UT, 2016, vol. AIAA 2016-4941.

[8] D. A. Herman, W. Santiago, H. Kamhawi, J. E. Polk, J. S. Snyder, R. R. Hofer, and M. J. Sekerak, "The Ion Propulsion System for the Asteroid Redirect Robotic Mission," in 52nd AIAA/SAE/ASEE Joint Propulsion Conference.

[9] J. Wang, D. E. Brinza, D. T. Young, J. E. Nordholt, J. E. Polk, M. D. Henry, R. Goldstein, J. J. Hanley, D. J. Lawrence, and M. Shappirio, "Deep Space One Investigations of Ion Propulsion Plasma Environment," J. Spacecr. Rockets, vol. 37, no. 5, pp. 545-555, 2000.

[10] D. Bromaghim, W. A. Hargus, J. W. Koo, M. Nakles, M. Scharfe, T. A. Smith, M. Venner, W. M. McKeon, R. B. Lyons, R. J. Adams, T. J. Lawrence, W. W. Saylor, S. Hart, M. G. McHarg, R. L. Balthazor, M. E. Dearborn, A. R. Vasso, K. I. Kalamaroff, A. GarrisonDarrin, R. Ossiander, L. T. Byrne, V. H. Hruby, and L. Johnson, "Overview of the FalconSat-5 Mission Propulsion Technology Applications to the Space Situational Awareness Mission Area," in JANNAF 6th 
Modeling and Simulation, 4th Liquid Propulsion, 3rd Spacecraft Propulsion Joint Subcommittee Meeting, Orlando, FL, 2008.

[11] J. Singleton, D. Connolly, D. Bromaghim, and L. Johnson, "Flight Summary of Spacecraft-Thruster Interactions on TacSat-2," JANNAF J. Propuls. Energ., vol. 4, no. 1, pp. 103-113, 2011.

[12] J. K. Ziemer, J. Ervin, and J. Lang, "Exploring Mission Concepts with the JPL Innovation Foundry A-Team," in AIAA SPACE 2013 Conference and Exposition, San Diego, CA, USA, 2013, vol. AIAA 2013-5431.

[13] A. L. Ortega, I. Katz, I. G. Mikellides, and D. M. Goebel, "Self-Consistent Model of a High-Power Hall Thruster Plume," IEEE Trans. Plasma Sci., vol. 43, no. 9, pp. 2875-2886, Sep. 2015.

[14] A. L. Ortega, W. Huang, I. G. Mikellides, and I. Katz, "A self -consistent numerical code for high-power Hall thruster plumes: improvements, validation, and integration with spacecraft interactions code," in Spacecraft Charging Technology Conference, Netherlands, 2016, vol. (poster).

[15] R. A. Dressler, Y. Chiu, O. Zatsarinny, K. Bartschat, R. Srivastava, and L. Sharma, "Near-infrared collisional radiative model for Xe plasma electrostatic thrusters: the role of metastable atoms," J. Phys. Appl. Phys., vol. 42, no. 18, p. 185203, 2009.

[16] M. R. Nakles, M. R. Holmes, and W. A. Hargus, "An Investigation into the Spectral Imaging of Hall Thruster Plumes," presented at the 30th International Symposium on Space Technology and Science, 34th International Electric Propulsion Conference and 6th Nano-satellite Symposium, Kobe, Japan, 2015, vol. IEPC-2015-416.

[17] R. Rajput, A. Khaustova, and A. Loyan, "Development of xenon collisional radiative model for plasma diagnostics of Hall Effect thrusters," East.-Eur. J. Enterp. Technol., vol. 2, no. 8 (86), pp. 24-29, 2017.

[18] C. C. Farnell, C. C. Farnell, S. C. Farnell, and J. D. Williams, "Recommended Practice for Use of Electrostatic Analyzers in Electric Propulsion Testing," J. Propuls. Power, vol. 33, no. 3, pp. 638658, 2017.

[19] G. B. Andrews, T. H. Zurbuchen, B. H. Mauk, H. Malcom, L. A. Fisk, G. Gloeckler, G. C. Ho, J. S. Kelley, P. L. Koehn, T. W. LeFevere, S. S. Livi, R. A. Lundgren, and J. M. Raines, "The Energetic Particle and Plasma Spectrometer Instrument on the MESSENGER Spacecraft," Space Sci. Rev., vol. 131, no. 1-4, pp. 523-556, Aug. 2007.

[20] W. Huang and R. Shastry, "Analysis of Wien filter spectra from Hall thruster plumes," Rev. Sci. Instrum., vol. 86, no. 7, p. 073502, Jul. 2015.

[21] R. R. Hofer, H. Kamhawi, I. G. Mikellides, Herman, Daniel, J. E. Polk, W. Huang, J. Yim, J. Myers, and R. Shastry, "Design Methodology and Scaling of the 12.5 kW HERMeS Hall Thruster for the Solar Electric Propulsion Technology Demonstration Mission," in 62nd JANNAF Propulsion Meeting, Nashville, TN, 2015, vol. JANNAF-2015-3946.

\section{BIOGRAPHY}

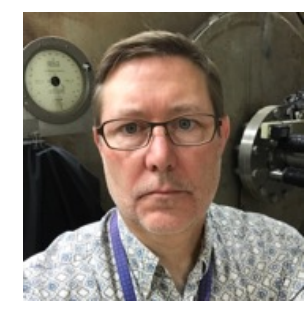

Lee Johnson received a B.S. from Harvey Mudd College in 1982 and a Physics Ph.D. from Rice University in 1987. He is a supervisor and researcher in JPL's Propulsion, Thermal, and Materials Engineering Section, and is responsible for research on electric thrusterspacecraft interactions with an emphasis on flight measurements and modeling. He participated in the ARGOS, REX-II, ESEX, TEX, Tacsat-2, AEHF-2, JIMO, Falconsat-5, Falconsat-6, and ARRM flight system activities for the USAF and NASA. He is an author of more than 60 technical and scientific papers.

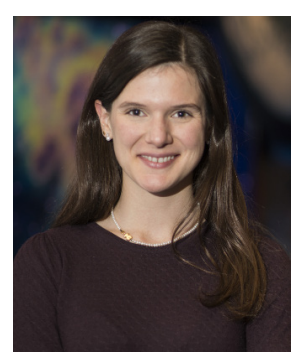

Maria de Soria-Santacruz Pich received an Aeronautics and Astronautics Ph.D. in from MIT in 2014. During 2014 she was a Postdoctoral Scholar at UCLA working on the development of an energetic particle detector for the ELFIN satellite and on the analysis of Van Allen Probes data. She joined JPL in 2015, where she has worked on the definition of space radiation environments, she has supported radiation analyses and testing for multiple instruments, and she was a member of the PDP development team. In 2017, she joined the Psyche project as a Payload Systems Engineer for the magnetometer instrument. Her interests include space environments, particles and fields instrumentation, and space systems.

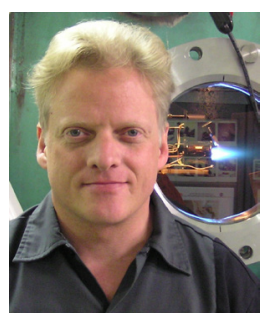

David Conroy received a B.S. in Chemistry from the University of Washington in Seattle, WA in 1994, then a Ph.D. in Chemical Physics from the University of Southern California in Los Angeles, CA in 2000. He has been with JPL since then. For his first flight project, he designed, delivered, and operated an ion energy spectrometer which flew on the Air Force experimental spacecraft TacSat-2. He also participated in the software development team for integration with subsystem and spacecraft systems, as well as formulating the flight operational procedures. He designed the gas inlet and pre-concentration subsystem of the Vehicle Cabin Atmosphere Monitor (VCAM) instrument, which operated successfully on board the International Space Station for two years, starting in June 2010. Dr. Conroy is currently serving as the Instrument Engineer for the Ultraviolet Spectrograph instrument being developed for the Europa Clipper mission to Jupiter's moon. 


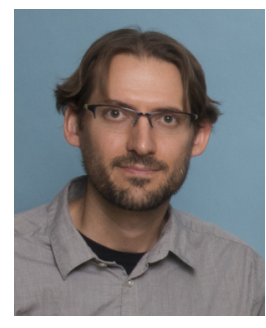

Robert Lobbia received B.S. degrees in Physics and Aerospace Engineering from the University of California, Los Angeles in 2003 and a PhD in Aerospace Engineering from the University of Michigan in 2010. He has been with JPL since 2016, where he has worked in the Electric Propulsion Group leading multiple experimental test campaigns supporting the HERMeS Hall thruster for the Advanced Electric Propulsion System development as well as being a member of the PDP development team. Prior to JPL, he worked at the Air Force Research Laboratory on plasma diagnostics, ground testing, flight software, on-orbit operation, and analysis of the Advanced Propulsion Instruments for the AEHF-2 spacecraft.

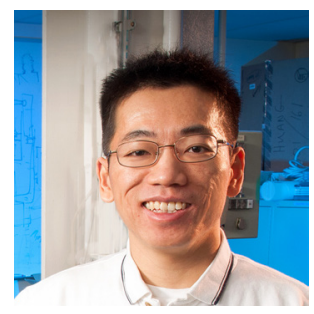

Wensheng Huang received B.S. degrees in Mechanical and Nuclear Engineering from the University of California, Berkeley in 2006. He received a Ph.D. in Aerospace Engineering from the University of Michigan in 2011. He performed his dissertation work on the use of optical diagnostics to study Hall thruster erosion under the tutelage of Prof. Alec D. Gallimore. He is currently a researcher in the Electric Propulsion Systems branch at the NASA Glenn Research Center. His present work include the development and testing of the Solar Electric Propulsion HERMeS Hall thruster and the Advanced Electric Propulsion
System, as well as ground and flight diagnostics for said systems.

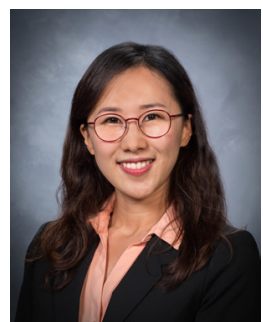

Maria Choi received a B.S. in Mechanical Engineering from Clarkson University in 2011 and a Ph.D. in Aerospace Engineering from the University of Michigan in 2016. She has been with the Electric Propulsion Systems Branch at NASA Glenn Research Center since 2015, where she has performed Hall thruster plume simulations for spacecraft contamination and system integration.

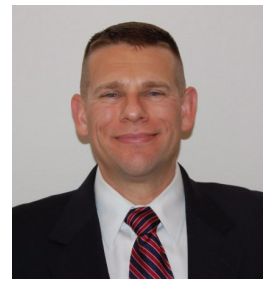

Michael Sekerak received a B.S. in Mechanical Engineering from Illinois Institute of Technology in 1999, a M.S. in Aeronautics from California Institute of Technology in 2001, and a Ph.D. in Aerospace Engineering from the University of Michigan in 2014. He was a former Armored Cavalry officer in the Army completing a combat tour in Iraq and was a Deputy Commander of the Missile Warning Center in Cheyenne Mountain. He has served at the National Security Space Institute, the Air Force Research Laboratory and the Air Force Office of Scientific Research as an Air Force Reserve Officer. He has worked at Sandia National Laboratories, the NASA Jet Propulsion Laboratory, and is currently at the NASA Goddard Space Flight Center where he is a Mission Systems Engineer. 